\title{
Propulsion System Choices and Their Implications
}

\author{
Claude R. Joyner II ${ }^{1}$ \\ Pratt \& Whitney Rocketdyne, West Palm Beach, Florida, 33410 \\ Daniel J. H. Levack ${ }^{2}$ \\ Pratt \& Whitney Rocketdyne, Canoga Park, California, 91309 \\ Russel E. Rhodes ${ }^{3}$ \\ NASA, Kennedy Space Center, Florida, 32899 \\ John W. Robinson ${ }^{4}$ \\ The Boeing Company, Huntington Beach, California, 92647
}

\begin{abstract}
In defining a space vehicle architecture, the propulsion system and related subsystem choices will have a major influence on achieving the goals and objectives desired. There are many alternatives and the choices made must produce a system that meets the performance requirements, but at the same time also provide the greatest opportunity of reaching all of the required objectives.

Recognizing the above, the SPST Functional Requirements subteam has drawn on the knowledge, expertise, and experience of its members, to develop insight that will effectively aid the architectural concept developer in making the appropriate choices consistent with the architecture goals. This data not only identifies many selected choices, but also, more importantly, presents the collective assessment of this subteam on the "pros" and the "cons" of these choices. The propulsion system choices with their pros and cons are presented in five major groups.

A. System Integration Approach. Focused on the requirement for safety, reliability, dependability, maintainability, and low cost.

B. Non-Chemical Propulsion. Focused on choice of propulsion type.

C. Chemical Propulsion. Focused on propellant choice implications.

D. Functional Integration. Focused on the degree of integration of the many propulsive and closely associated functions, and on the choice of the engine combustion power cycle.

E. Thermal Management. Focused on propellant tank insulation and integration.
\end{abstract}

Each of these groups is further broken down into subgroups, and at that level the consensus pros and cons are presented.

The intended use of this paper is to provide a resource of focused material for architectural concept developers to use in designing new advanced systems including college design classes. It is also a possible source of input material for developing a model for designing and analyzing advanced concepts to help identify focused technology needs and their priorities.

\footnotetext{
${ }^{1}$ Technical Fellow, Systems Analysis, P.O. Box 109600 MS712-67, AIAA Associate Fellow.

${ }^{2}$ Program Manager, Advanced Programs, P.O. Box 7922 / MS RFB19, AIAA Member.

${ }^{3}$ AST, Technical Management, Engineering Directorate Design \& Development Eng Div Sys Engineering \& Integration Br, Kennedy Space Center, Florida/NE-D2, AIAA Senior Member.

${ }^{4}$ Principal Engineer/Scientist, Propulsion Engineering, 5301 Bolsa Avenue/H013-C313, AIAA Associate Fellow. 


\section{Nomenclature}

\begin{tabular}{|c|c|}
\hline $\mathrm{ACS}$ & $=$ Attitude Control System \\
\hline $\mathrm{CG}$ & $=$ Center of Gravity \\
\hline EDT & $=$ Electrodynamic Tether \\
\hline EMA & $=$ Electro Mechanical Actuator \\
\hline ETO & $=$ Earth-to-Orbit \\
\hline DDT\&E & $=$ Design, Development, Test and Evaluation \\
\hline EP & $=$ Electric Propulsion \\
\hline FLOX & $=$ Fluorine-Oxygen \\
\hline GEO & $=$ Geosynchronous Earth Orbit \\
\hline GLOW & $=$ Gross Lift Off Weight \\
\hline GSE & $=$ Ground Support Equipment \\
\hline HAN & $=$ Hydroxyl Ammonium Nitrate \\
\hline IRFNA & $=$ Inhibited Red Fuming Nitric Acid \\
\hline Isp & $=$ Specific Impulse \\
\hline IVHM & $=$ Integrated Vehicle Health Management \\
\hline LEO & $=$ Low earth orbit \\
\hline LNG & $=$ Liquid Natural Gas \\
\hline MEO & $=$ Medium earth orbit \\
\hline $\mathrm{MMH}$ & $=$ Monomethylhydrazine \\
\hline MPD & $=$ Magneto-Plasma Dynamic \\
\hline NBP & $=$ Normal Boiling Point \\
\hline NEP & $=$ Nuclear Electric Propulsion \\
\hline NEVRA & $=$ Nuclear Engine for Rocket Vehicle Application \\
\hline NTP & $=$ Nuclear thermal propulsion \\
\hline OMS & $=$ Orbital Maneuvering System \\
\hline $\mathrm{R}$ & $=$ Radius \\
\hline $\mathrm{RCS}$ & $=$ Reaction Control System \\
\hline RLV & $=$ Reusable Launch Vehicle \\
\hline RP-1 & $=$ Refined Petroleum-1 (highly refined kerosene) \\
\hline SPST & $=$ Space Propulsion Synergy Team \\
\hline SRM & $=$ Solid Rocket Motor \\
\hline SSTO & $=$ Single Stage to Orbit \\
\hline STS & $=$ Space Transportation System \\
\hline $\mathrm{T}-0$ & $=$ Time Equal Zero \\
\hline TRL & $=$ Technology Readiness Level \\
\hline TVC & $=$ Thrust Vector Control \\
\hline U.S. & $=$ United States \\
\hline UAH & $=$ University of Alabama at Huntsville \\
\hline UDMH & $=$ Unsymmetrical Dimethylhydrazine \\
\hline
\end{tabular}

\section{Introduction}

T $\mathrm{N}$ defining a space vehicle architecture, the propulsion system and related subsystem choices will have a major influence on achieving the goals and objectives desired. There are many alternatives and the choices made must produce a system that meets the performance requirements, but at the same time also provide the greatest opportunity of reaching all of the required objectives.

Recognizing the above, the SPST Functional Requirements subteam has drawn on the knowledge, expertise, and experience of its members, to develop insight that will effectively aid the architectural concept developer in making the appropriate choices consistent with the architecture goals. This data not only identifies many selected choices, but also, more importantly, presents the collective assessment of this subteam on the "pros" and the "cons" of these choices. The propulsion system choices with their pros and cons are presented in five major groups. 
A. System Integration Approach. Focused on the requirement for safety, reliability, dependability, maintainability, and low cost.

B. Non-Chemical Propulsion. Focused on choice of propulsion type.

C. Chemical Propulsion. Focused on propellant choice implications.

D. Functional Integration. Focused on the degree of integration of the many propulsive and closely associated functions, and on the choice of the engine combustion power cycle.

E. Thermal Management. Focused on propellant tank insulation and integration.

Each of these groups is further broken down into subgroups, and at that level the consensus pros and cons are presented.

The intended use of this paper is to provide a resource of focused material for architectural concept developers to use in designing new advanced systems including college design classes. It is also a possible source of input material for developing a model for designing and analyzing advanced concepts to help identify focused technology needs and their priorities.

It is important to remember that the information presented should be considered independently and the Pro's and Con's might vary when considered in combinations.

\section{System Integration}

The first section presented is system integration. The section is presented as eight areas. First is the vehicle configuration and propellant tanks area which concerns the placement of the tanks such as lox tank aft or forward, parallel tanks, toroidal tanks, etc. The second area is the propulsion system engine propellant feed technique area which concerns pressure fed versus pump fed and what type of pump. The third area is the propellant transfer pump location area which discusses where the pumps might be placed. The fourth area is the functionally optimizing propulsion components versus traditional stand-alone rocket engine area. This area discusses how many turbopump sets should be associated with how many thrust chamber assemblies (1:1, many:1, 1:many, many:many). The fifth area is the main rocket engine start considerations area where different start methods are discussed. The sixth area is the rocket engine and motor ignition system area which presents ignition methods. The seventh area discusses the number of main rocket nozzles and their placement. The last area discusses structural design options of the aft end of the vehicle.

\section{A. System Integration for Safety, Reliability, Dependability, Maintainability, and Low Cost Considerations \\ 1. Vehicle Configuration of Propellant Tanks \\ 1.1 Tandem Lox Tank Forward / Fuel Tank Aft}

Of NASA vehicles, only the Saturn IC booster stage has used this tank arrangement.

Pros: This tank arrangement places the more massive tank higher in the vehicle stack. In turn, this moves the vehicle CG forward. Moving the vehicle CG forward results in a decrease in the gimbal angle needed to produce a given control moment. Alternately, it provides greater control authority of the vehicle at a given engine gimbal angle when in need of steering. It also reduces the performance loss when thrusting through the CG of the vehicle with multiple off-axis engines. Additionally, if engines are mounted on a single plane and thrusting through the CG, the flight attitude angle is less with respect to the vertical axis of the vehicle and again the gimbal angles required for control are less with the greater moment arm length.

Cons: This tank arrangement requires long lox propellant feed lines. This leads to cryogenic geysering and resulting water hammer loads during ground servicing, vehicle pogo in flight, and engine turbo-pump and feed system thermal conditioning for engine start. All three of these conditions require active sub-systems to accommodate, i.e., lox anti-geysering system, pogo suppression system, and a propellant thermal conditioning system. In addition to these added subsystems, the servicing process is much longer and requires process control to maintain a safe vehicle, e.g., lox chill-down to remove the sensible heat of the feed system and engine/feed system interface to avoid an uncontrolled geyser during loading, a slow fill loading of the feed system to avoid damage of the tank outlet anti-vortex hardware, and possible feed system drain-back conditioning just before engine start. 
These constraints compromise hold time flexibility and require active systems with fault tolerance to avoid loss of vehicle. A constraint is also placed on the ground lox-servicing system to condition or avoid warm lox temperatures or two-phase flow at the flight vehicle interface at all times. The required subsystems add considerable hardware, added weight, non-recurring hardware cost, ground support infrastructure, consumables, considerable maintenance burden/cost and time, and sustaining engineering burden/cost.

If the vehicle propellant tanks carry the load through the base, the fuel tank will be required to have the strength/mass to support the lox tank resulting in added weight.

For turbopumped engines on a booster stage, placing the fuel tank aft reduces the pressure head available to the fuel pump at start. The reduction in available head may result in decreased pump speed (higher turbopump weight), a need for a boost pump (increased engine weight), or an increase in required tank pressure. If the tank pressure is increased the pressurant system weight increases and the tank weight may increase if the pressurant pressure is the controlling parameter in the tank wall thickness. Because of its density the lox turbopump generally has sufficient head in a booster application.

\subsection{Tandem Fuel Tank Forward / Lox Tank Aft}

Pros: All U.S. rocket-powered vehicles flew this choice before the Saturn vehicle and consequently a good database exists. All the Con's identified for the choice above are eliminated except a slow fill loading of the feed system to avoid damage to the tank outlet anti-vortex hardware and possible pogo if the engine mounting arrangement allows flexing of the support structure. The lower lox head allows use of much simplified lox servicing hardware (possibly using a transfer without pumps using only facility pressure). Engine start conditioning can be accomplished by simple helium bubbling system.

Cons: Lower CG and possible resultant performance loss (see pro's in item 1.1 above) and, if fuel is cryogenic, the conditioning requirements are more critical because of longer feed-line.

\subsection{Parallel Fuel and Lox Tanks}

Pros: This tank arrangement was demonstrated on the Saturn I and IB vehicles. The low propellant head allows simple ground servicing (possibly using a transfer without pumps using only facility pressure) avoiding water hammer. For cryogenic fluids, damage can occur when slugs of liquid are expelled at significant velocity by gas that is generated by heat leaks into the long propellant transfer line. This is called slug flow damage and is minimized by reducing the head that must be supplied by the propellant feed system. Tank arrangements that do not have one tank above the other minimize this problem. This tank arrangement avoids slug flow damage. Avoids geysering and pogo issues and added flight systems. Reduces cryogenic chill-down complexity and time.

Cons: Lower CG and possible resultant performance loss (see pro's in item 1.1 above).

\subsection{Hybrid Fuel and Lox Tanks, e.g., Toroidal/Cylindrical Combination}

Pros: Low propellant head allows simple ground servicing (possibly using a transfer without pumps using only facility pressure) avoiding water hammer and slug flow damage from ground system head changes (cryogenic fluids). Avoids geysering and pogo issues and added flight systems. Reduces cryogenic chill-down complexity and time. Engine start conditioning can be accomplished by simple helium bubbling system.

Cons: Lower CG and possible resultant performance loss (see pro's in item 1.1 above). Toroidal tanks are generally heavier than cylindrical tanks.

\subsection{Hybrid Fuel and Lox Tanks, e.g. Oxidizer Tank Within Fuel Tank Both with External} Access for Feed System

Pros: Will allow better flight hardware packaging density for upper-stage applications. Provides a design with less external exposure to the environment.

Cons: Will drive complexity considerably where the fuel/oxidizer delta temperatures are not low, e.g., double walled oxidizer tank for thermal isolation purposes. Concerns for fault tolerance for safety reasons will either complicate the design or drive the operational verification process between flights. The two tanks arranged this way may be heavier than two separate, non-enclosed,

4

American Institute of Aeronautics and Astronautics 
tanks, but the packaging probably will be more efficient. Because this design has less external exposure to the environment, it may cause concerns for frost or ice accumulation during ground servicing, which could result in added liftoff weight or needed environmental protection systems.

\section{Propulsion System Engine Propellant Feed Technique}

\subsection{Turbopumps}

This is the traditional approach for large thrust main propulsion systems. All comparisons are versus pressure fed systems.

Pros: The advantage of any pumped rocket engine is that it allows greatly increased thrust in a given envelope which reduces engine weight. It also allows a much higher area ratio in a given envelope which, in turn, produces much higher specific impulse thus decreasing vehicle weight. The pumps allow the propellant tanks to operate at a low pressure. The low tank pressure produces a low tank weight and a low pressurant system weight relative to a pressure fed system. If the pump drive source is a turbine, then the feed technique is a "turbopump". A turbopump produces the highest power density (horsepower per pound of pump and drive source) of any of the available propellant feed techniques. Turbopumps allow flexibility in the choice of engine power cycle.

Cons: Turbopumps add cost, complexity, and parts, all of which lead to decreased reliability compared to pressure fed systems. Turbopump engines are more difficult to start and shut down safely. They require pump chill down for cryogenic propellants. Depending on the engine power cycle and propellant choice, shaft seal leakage of the lox pump requires hazard control sub-system support (purge) and also allows atmosphere entry following shutdown, which requires drying and corrosion control throughout the ground processing cycle.

\subsection{Tank Pressure Transfer}

Pressure fed systems have been used for many moderate thrust main propulsion systems and for most small thrusters.

Pros: This choice is simple to service, has less components, and is more reliable and maintainable than pumped systems.

Cons: Higher engine weight and considerable performance loss. Tankage and pressurant system weights may be much higher.

\subsection{Reciprocating Pumps}

Pros: May allow more operationally favorable pump drive solution, e.g., electric vs. turbine.

Cons: Only usable for high head, low flow applications, thus likely to have limited applications such as stationkeeping or ACS/RCS. Possibly usable for non-continuous higher flowrate applications if an accumulator is used.

\subsection{Electric Motor-Driven Pumps}

Pros: Replacing the turbine and all of the turbine drive fluid generating components allows high pressure combustion with increased performance efficiency and with a simple approach. This may provide increased reliability/dependability/safety and lower life cycle cost.

Cons: Adds an electrical generation and supply system. Probably results in a weight increase for moderate or higher thrust engines and the weight increase will be very sensitive to the required horsepower and required electrical power generation and supply system. Materials capability with lox could result in safety control concerns.

\section{Propellant Transfer Pump Location}

\subsection{Pumps Integrated with Combustion Components}

Pros: Traditional way of doing business provides ease of procurement and engine development management. Minimizes routing lengths of turbine drive fluid lines. Since these lines are often both high pressure and hot, minimizing their length minimizes engine weight.

Cons: Requires long cryogenic chill-down to remove the sensible heat before loading the propellant. Heat input from pump mass can cause geysering and requires an active system for prevention. Requires an active system to condition the propellant in the pumps for engine start conditions (re-circulating pumps and valves, active bleed flow valves, or helium bubbling). 


\subsection{Pumps Integrated with Propellant Tanks (Located in Tank Sump)}

Pros: Can service (fill and drain) directly into the sump avoiding the extended cool-down and allowing faster propellant servicing. Deletes requirement for anti-geysering, pogo, and pump conditioning systems for engine start. Integrates best with the parallel and hybrid propellant tank configuration choices. Deletes traditional pre-valves, therefore saving weight, increasing safety of flight, reliability, and reducing recurring cost.

Cons: Requires a long line for turbine drive gas from the engine to the pump thus increasing weight. Places hot gas much neared to propellant tanks. Pump failure cannot be isolated from propellant in tank causing safety concerns at stage element test facilities if being used during DDT\&E cycle.

\subsection{Pumps Mounted on Vehicle Structure Separate from Engine Combustion Hardware}

Pros: Hardware location should provide greater ease of access for maintenance.

Cons: May be limited to the gas generator or expansion cycle engine choices (Atlas, Jupiter and Thor vehicles). Likely to result in an engine weight increase and does not delete the conditioning system requirements for either engine start or tank filling. It also does not delete the concerns for geysering/water hammer or the need to perform the fill servicing process with added chill-down time to remove the sensible heat of mass before filling the tanks. Also will add need for structural verification of high-pressure flex joints between flights.

\section{Functionally Optimizing Propulsion Components versus Traditional Stand-Alone Rocket Engine}

The traditional U.S. approach is to build engines with a single set of turbopumps feeding a single thrust chamber assembly and to have an engine controller on the engine. There are alternate approaches. A single turbopump set can feed multiple thrust chamber assemblies (some Russian engines operate this way); multiple turbopump sets can feed a single thrust chamber assembly; multiple turbopump sets can be associated with multiple thrust chamber assemblies using ring manifolds where no particular turbopump set (or even individual turbopump) is associated with a particular thrust chamber assembly. And controllers can be at the multiple engine level or at the vehicle level. For the discussions below, the comparisons are for different approaches for the same thrust level and same envelope.

4.1 Traditional Engine: One Turbopump Set, One Thrust Chamber Assembly (1:1)

Pros: Traditional U.S. way of doing business except for the Atlas designed in 1950's that flew for over 40 years that use one set of turbo-pumps to feed two combustion chamber/nozzles as a booster system that was staged during flight. Dynamics perceived to be easier to design, control, and analyze resulting in lower DDT\&E cost. Minimum amount of active hardware increases reliability and reduces maintenance burden.

Cons: Any failure of turbopump or thrust chamber assembly takes engine off line. Lower rate of production (compared to approaches below) of turbopump sets and thrust chamber assemblies will increase costs.

\subsection{One Turbopump Set that Feeds Multiple Thrust Chamber Assemblies (1:many)}

Pros: Individual thrust chamber assemblies can be isolated such that failure of a thrust chamber assembly does not take engine off line. Higher rate production of thrust chamber assemblies could lower cost. Physically smaller thrust chamber assemblies probably less expensive to produce. Can get higher area ratio within a given length envelope and thus higher specific impulse. Overall reliability could increase.

Cons: Increased amount of active hardware decreases reliability and increases maintenance burden. More interconnection hardware will add cost and weight. There is an increase in the amount of active hardware. This will increase the maintenance burden and ground support costs especially for reusable systems. Overall reliability could decrease. Overall engine thrust-to-weight probably decreases.

Since the reliability is being driven both up and down, a full set of system trades will be needed to determine the reliability impact for a given application.

6

American Institute of Aeronautics and Astronautics 
4.3 Multiple Turbopump Sets that Feed One Thrust Chamber Assembly (many:1)

Pros: Individual turbopump sets (or even individual turbopumps) can be isolated such that failure of a turbopump does not take engine off line. Higher rate production of turbopumps could lower cost. Physically smaller turbopumps are probably less expensive to produce. Small turbopumps will probably weight less per horsepower because they can be designed to run faster.

Cons: Increased amount of active hardware decreases reliability and increases maintenance burden. More interconnection hardware will add cost and weight. There is an increase in the amount of active hardware. This will increase the maintenance burden and ground support costs especially for reusable systems. Overall reliability could decrease. Overall engine thrust-to-weight probably decreases.

Since the reliability is being driven both up and down, a full set of system trades will be needed to determine the reliability impact for a given application.

4.4 Multiple Turbopump Sets that Feed Multiple Thrust Chamber Assemblies (many:many)

Pros: Individual turbopump sets (or even individual turbopumps) and individual thrust chamber assemblies can be isolated such that their failures do not take the engine off line. Higher rate production of turbopumps and thrust chamber assemblies could lower cost. Physically smaller turbopumps and thrust chamber assemblies probably less expensive to produce. Small turbopumps will probably weight less per horsepower because they can be designed to run faster.

Cons: Increased amount of active hardware decreases reliability and increases maintenance burden. More interconnection hardware will add cost and weight. There is an increase in the amount of active hardware. This will increase the maintenance burden and ground support costs especially for reusable systems. Overall reliability could decrease. Overall engine thrust-to-weight probably decreases.

Since the reliability is being driven both up and down, a full set of system trades will be needed to determine the reliability impact for a given application.

\subsection{Integrated Multiple Rocket Engine/Vehicle Control Component versus Dedicated Engine Controller Components}

Pros: Reduction of hardware components will increase the reliability, reduce the maintenance burden, and provide lower life cycle cost. In relation to Shuttle, this approach would also delete the interface units for each engine required to provide vehicle to engine compatibility.

Cons: Total rocket engine stand-alone capability will be lost. Engine development and depot maintenance testing will require the use of GSE to perform this control function. Engine certification of readiness will require understanding and adjustment from today's approach.

\section{Main Rocket Engine Start Considerations}

5.1 Traditional Fast Ramp Start

Pros: Conserves propellant during startup. Minimizes need for shutdown control on previous stage (for non-booster stages).

Cons: Produces rapid temperature changes in components that result in shortened engine life without sophisticated design for reduce thermal strains. Combustion stability must be considered relative to the start transient when using hydrocarbon fuels.

\subsection{Soft Start with Ramp to Mainstage}

Pros: Decreases temperature change rate on hardware and increases design life. May increase system availability for reusable systems. This approach was used on early systems like the Jupiter vehicle. Provides opportunity for engine system health check before launch commit.

Cons: Performance losses during engine start as engines consume more propellant before lift-off. Conditions for ignition and combustion stability dictate the minimum power level that can be tolerated. Conditions are highly dependent on the fuel and oxidizer choice and combustion pressure. 


\subsection{Traditional Fast Shutdown}

Pros: Minimizes impulse during shutdown. Helps to avoid impacting next stage during its startup.

Cons: Typically done for $\mathrm{O}_{2} / \mathrm{H}_{2}$ stages by shutting lox valve very quickly. This produces very rapid cold quench on turbine blades producing high strain. This may not matter for expendable engines, but will decrease life for reusable engines.

\subsection{Soft Shutdown from Mainstage}

Pros: Eliminates high strains on turbine blades. Increases engine life for reusable applications.

Cons: Increases shutdown impulse. Increases chance of impacting next stage during its start or requires active system to move stage away from next stage trajectory.

\subsection{Tank Head Start}

Propellants are delivered to the main combustion chamber at low pressure and ignited - essentially a pressure fed start. Then the turbopumps are bootstrapped using whatever turbine drive fluid is used for the given engine power cycle.

Pros: One of the simplest and lowest part count approaches. Can use any quality propellants thus allowing for starts or restarts in gravity or zero gravity environments. Provides opportunity for engine system health check before ramp-up to full chamber pressure. The tank head start without ramp-up to full pressure can be used to settle propellants in an upper stage application, thus eliminating the need for a separate system.

Cons: Requires more start transition time and consumes more propellants during the start sequence. Results in small loss in performance. Requires greater tank head capability (possibly resulting in a heavier tank).

\subsection{Turbine-Spin System}

Pros: Small performance gain as this approach minimizes the propellants consumed during the start sequence. Alternative to spinning main turbine is to spin start a "boost turbine/pump" assembly and use this as the pressurization and start system for the main-stage turbopump. This could consume less pressurization fluids than starting the main-stage, higher flow turbine/pump assemblies:

Cons: Requires added gas spin support system on the vehicle to provide vehicle restart and a ground infrastructure to support this added vehicle system. Increases hardware parts count decreasing dependability and increasing cost.

\subsection{Hypergolic Expendable Cartridge System}

Pros: Hypergolic ignition approach is very dependable when system operates correctly. Was used on Apollo/Saturn IC's F-1 engine.

Cons: Cartridges are expendable and require replacement after each firing. Safety issues as hypergolic cartridges are toxic if leakage occurs and requires added safety precautions when handling. Will require added IVHM for reusable maintenance.

\subsection{Pyrotechnic Expendable Cartridge System}

Pros: Pyrotechnic (e.g. Potassium Perchlorate, Ammonium Nitrate, Aluminum, Black Powder, etc.) ignition is fast, and generally reliable and the materials are generally less toxic than the hypergols. Cartridges can be used in a set for multiple starts. Technology is at a very high TRL (89) and used in flight systems.

This choice is considered standard for solid motors.

Cons: Ignition produces particles that can impact turbine if used as a gas generator start system as well as the chamber walls if used for the main chamber. This can present issues for reusable applications and for regeneratively cooled chambers in terms of possible damage to the coolant passages/inner walls. This choice will require maintenance (inspections) between every engine firing and will result in reduced engine life. This concept will result in considerable increased operating cost and decreased responsiveness.

\section{Rocket Engine and Motor Ignition System}

Hypergolic propellants do not need ignition systems. 


\subsection{Hypergolic Ground Supplied System}

Pros: Eliminates the need for vehicle access to replace the expendable engine supplied cartridge in the event of an on-pad abort or between flights while maintaining the dependability of the hypergolic technique for engine start.

Cons: This choice adds a considerable safety and life cycle cost concern, e.g., there is an additional fluid that requires a unique flight to ground umbilical. This umbilical will function for each engine at start. The system puts additional complexity into the launch system relative to safety, cleanliness, and the launch and abort umbilical connect/disconnect. This design approach will require a T-0 umbilical fluid system supporting each engine. This design choice also will add additional infrastructure to support this toxic fluid and the resultant added life cycle cost and safety risk of a T-0 umbilical system. A T-0 system will most likely require re-cleaning between flights. Use of this type of start system is limited to only the vehicle's first stage element.

\subsection{Augmented Spark Igniter System (Sometimes Referred to as Torch System)}

Pros: Presently used on the Shuttle SSME. It is very dependable and supports reusability without maintenance between firings. This choice is considered standard for hybrid solid fuel systems. Choice is under consideration for hydrocarbon fuels to support reusability, but presently technology has not been demonstrated in a rocket engine, but it's very mature and standard for gas turbine engines.

This choice was used on the J-2 and RL-10 Lox/ $\mathrm{LH}_{2}$ engines supporting the Saturn and Centaur vehicles. It works well with $\mathrm{Lox} / \mathrm{LH}_{2}$ because of their large flammability range and high flame speed. The spark ignition technique is used to ignite the torch.

Cons: Technology is at very low TRL level for use in hydrocarbon fuels in a rocket engine, as feasibility has not been established.

Torch must be "started" ahead of main chamber start, which complicates the main chamber primary and secondary flow paths. Restart can be an issue since supply cavities and Torch cavity could freeze from residual oxidizer flow between starts. Typically means going to a gaseous oxidizer flow versus liquid oxidizer flow when using cryogenic fluids.

6.5 Alternative Ignition Techniques for the Augmented Spark Igniter System - Microwave, Laser, or Hot-Wire Ignition

Pros: The microwave, laser, and hot wire techniques are alternatives to ignite the torch system and may be more desirable than the spark igniter approach, but should be considered only for the torch ignition application.

Cons: Use in hydrocarbon fuels may be slow and has not been demonstrated as dependable. The technology is at low TRL level for use in rocket engines, as the feasibility has not been established. This approach will need to be highly integrated into the combustion chamber design and increases the complexity of the combustion chamber design. The impact at the total vehicle system level and on the vehicle's electrical power system has not been defined.

\section{Number of Main Rocket Engine Nozzles and Their Placement}

7.1 Traditional Thinking to Use a Center Engine Nozzle to Help Control Exhaust Re-Circulation Heating Environment During Ascent

Pros: Design tools to analyze thermal heating of the aft compartment from exhaust flow and recirculation during ascent are available and the designer is comfortable with this choice.

Cons: Structural support deflection for the center engine during ascent can cause pogo. The presence of pogo requires a pogo-suppression system adding hardware over-and-above the additional engine and its support systems. This additional active hardware reduces the reliability and increases the maintainability burden resulting in added recurring and acquisition cost. Requirement doesn't allow the design concept to be optimized for the total number of engines and thrust size to find the best balance of dependability, safety, and maintainability to provide the best life cycle cost solution. Also the designer will be required to use aerodynamically contoured aft compartment to control/minimize the re-circulation and reduce the base drag.

\subsection{Only Use Rocket Engine Nozzles to Thrust Directly Through the Structure to Avoid Support Deflection During Ascent}


Pros: Aerodynamically contoured aft compartment to control/minimize the re-circulation and reduce the base drag should allow the deletion of the aft heat shield and provide an open aft compartment. An open aft compartment eliminates the need for closed compartment purge of both air for ground processing, $\mathrm{GN}_{2}$ for propellant loading, and the hazardous gas detection system. It allows access for maintenance without drag-on kits. This approach results in the deletion of the pogo sub-system. The deletion of this hardware will increase reliability, safety, and reduce the maintainability burden resulting in reduced life cycle cost.

Cons: Will require technology development and maturation of the understanding of open aft compartment/no heat shield environment and verification of that understanding.

\section{Structural Design of Aft End of Vehicle}

8.1 Use Traditional Aft Closed-Compartment with Base-Heat Shield and Flat-Plate Base Drag Pros: Design tools to analyze thermal heating of the aft compartment from exhaust flow and recirculation during ascent are available and the designer is comfortable with this choice. However, this choice suggests the use of a center engine to help control the aft heating environment.

Cons: This choice provides a closed compartment with inherent safety hazards. A closed aft compartment requires a closed compartment purge of both air for ground processing, $\mathrm{GN}_{2}$ for propellant loading, and a hazardous gas detection system. It requires the use of drag-on kits for maintenance. The addition of this hardware will decrease reliability, safety, and increase the maintainability burden resulting in increased life cycle cost.

\subsection{Provide Aerodynamic Vehicle Aft End to Allow Open Thrust Structure and No Base Heat Shield}

Pros: The use of an aerodynamically contoured aft compartment to control/minimize the recirculation and reduce the base drag should allow the deletion of the aft heat shield and provide an open aft compartment. An open aft compartment eliminates the need for closed compartment purge of both air for ground processing, $\mathrm{GN}_{2}$ for propellant loading, and the hazardous gas detection system. It allows access for maintenance without drag-on kits. This approach results in the deletion of the pogo sub-system. The deletion of this hardware will increase reliability, safety, and reduce the maintainability burden resulting in reduced life cycle cost.

Cons: Will require technology development and maturation of the understanding of open aft compartment/no heat shield environment and verification of that understanding.

\section{Non-Chemical Propulsion}

The next section is non-chemical propulsion. This section is presented in four areas. The first area is nuclear energy powered propulsion including nuclear thermal, nuclear electric, and bi-modal. The second area is solar energy powered propulsion including electric, sails and thermal. The third area discusses other propulsion thrusters including various electric thrusters and cold gas thrusters. The last area presents two types of propulsion tethers.

\section{B. Non-Chemical Propulsion Considerations}

1. Nuclear (Fission) Energy Powered Propulsion

1.1 Nuclear Thermal Expansion (NTP

Pros: High performance (Isp) $>850 \mathrm{sec}$ Isp, Thrust $>1000 \mathrm{lb}_{\mathrm{f}}$. Provides the high thrust of chemical systems but at $2 \mathrm{X}$ the Isp performance. Has less complexity in terms of mechanical systems than Nuclear Electric Propulsion (NEP). Work on fuel materials at the end of NERVA showed promise for Composite, Carbide-based, and CERMET fuels to retard fission product emission (near zero) and provide longer burn time capability $>5$-hours.

Cons: Safety major concern and difficulty to perform the DDT\&E (except very small scale below ground level) and to perform the ETO operations. Proven at prototype level only and previous graphite/carbide designs became politically unattractive due to release of fission particles in exhaust. Requires encapsulated testing and continued fuels development work to mature to a flight system. 


\subsection{Nuclear Electric with Thrusters (NEP)}

Pros: Very high performance (Isp) with major increases in payload fraction for planetary orbital, solar system, and possible interstellar missions (Isp from 3,000-10,000, Thrust from 0.002 to 0.5 $\left(b_{f}\right)$. Planetary trip time decreases compared to all chemical propulsion approaches. Potential to eliminate planetary swing-by requirements and increase payload delivery as well as decrease trip time.

Cons: No flight experience and many operational unknowns associated with this technology. Additional fluids and complex systems will challenge safety, mission reliability, and cost goals. Human missions require a chemical stage to rendezvous with NEP stage before escape to prevent penalties associated with the crew spending 100's of days on the spacecraft before Earth escape. The size of the NEP reactor typically sized for several Megawatts thermal and requires a large heat rejection radiator to eliminate power cycle waste heat. Due to the integrated space radiator requirements, a full-up system test cannot be performed on Earth and can the system can only be tested in a space at full size. This drives development cost and risk up. Although no direct fission product release because of the closed power-cycle to create the electric power, a "hot" reactor has fission product build-up over time. This can be an issue for operation in LEO or MEO either due to re-entry possibility or energetic particle flux emissions that could interfere with proximity operations with other spacecraft.

\subsection{Nuclear Bi-Modal with Thrusters}

Pros: High performance NTP thrust and Isp coupled with very high NEP Isp. Can deliver high thrust for earth escape with a short thrusting time thus reducing spiral out trajectory time of NEP. Uses EP thrusters by using fission reactor as a power source for electric thrusters after planetary escape. Significant planetary trip time and mission mass decrease compared to all chemical propulsion systems. Permits a "NEP" reactor to be tested on Earth first before a spaceflight because it is the same reactor used for NTP. Eliminates need for chemical crew stage for rendezvous versus pure NEP Earth departure stage.

Cons: This choice has all the Con's of the two choices above, except the size will allow the DDT\&E to be performed underground/encapsulated on earth

\section{Solar Energy Powered Propulsion}

\subsection{Solar Electric with Thrusters}

Pros: Mature technology that is mostly a passive system with high dependability and low cost. Flight proven with Deep Space 1 spacecraft.

Cons: Susceptible to space debris causing reduced performance. Limited to low performance/reasonable size. Power available diminishes with $1 / \mathrm{R}^{2}$ relative to moving away from sun. See Thruster discussions in Section 3.1 though 3.4 for more complete perspective.

\subsection{Solar Sails}

Pros: This approach is mostly a passive system, but limited to high earth orbit and beyond.

Cons: Very large structure and travel speed is very slow. No flight experience and low technology maturity. Material strength/density is a major challenge and plasma sail technology approach maturity is even less mature.

\subsection{Solar Thermal Expansion}

Pros: Propulsion energy conversion system very similar to nuclear (fission) thermal engine except that the reactor is replaced with a solar concentrator and safety and complexity is considerably improved. Materials available and required operate in much less severe environment providing higher dependability and lower life cycle cost. (Isp $>600 \mathrm{sec}$ with Hydrogen). Provides a cost effective approach for low-thrust, high-Isp unmanned systems due to size and reduced system complexity.

Cons: Energy heat source size limited to solar constant and collector size. Low thrust application only. No flight experience and technology at low maturity level. Vehicle is attitude limited to maximizing solar collectors orientation to Sun; therefore thrusting time must be managed. System size could be limited due to cavity scaling and materials limitations that constrain Isp capability 
since thermal energy is transferred directly from solar heat source via mechanical methods to the "cavity".

\section{Other Propulsion Thrusters}

3.1 Hall Effects Electrostatic Thrusters

Pros: Some spacecraft flight experience. High performance (Isp) with relatively high thrust/ power density. Use Xenon storable fluid that can be serviced off line without the use of a facilitated ground system. Low recurring cost. Isp $=2500 \mathrm{sec}$ at $4.5 \mathrm{kWe}$.

Cons: Requires high power to get increased efficiency and performance. Produces low thrust. Current technology is high specific mass $(\sim 10 \mathrm{~kg} / \mathrm{kw})$. These characteristics limit the applications to satellite or small spacecraft propulsion. Moderate thrust/power ratio, lower than arc-jets and resistojets.

\subsection{Ion Electrostatic Thrusters}

Pros: Considerable spacecraft flight experience. Very high performance (Isp). Uses storable fluids that can be serviced off line without the use of a facilitated ground system. Low recurring cost. Isp $=3200 \mathrm{sec}$ at $2 \mathrm{kWe}$.

Cons: Requires high power to get increased efficiency and performance. Produces low thrust. Current technology is high specific mass $(\sim 10 \mathrm{~kg} / \mathrm{kw})$. These characteristics limit the applications to satellite or small spacecraft propulsion. Lowest thrust/power of candidate EP devices.

\subsection{Arc-Jet Electrothermal Thrusters}

Pros: Second only to resistojets for spacecraft flight use experience. Uses storable fluids that can be serviced off line without the use of a facilitated ground system. Low recurring cost provided the fluid choice is not the toxic $\mathrm{N}_{2} \mathrm{H}_{4}$. Isp $=600 \mathrm{sec}$ with $\mathrm{N}_{2} \mathrm{H}_{4}$ at $2 \mathrm{kWe}$; Isp $=800 \mathrm{sec}$ with $\mathrm{NH}_{3}$ at $30 \mathrm{kWe}$.

Cons: Requires high power and has moderate performance limiting its application; however, produces higher Isp than the resistojet choice. Experience has been mostly with $\mathrm{N}_{2} \mathrm{H}_{4}$, which drives up the life cycle cost due to handling costs associated with it being toxic.

\subsection{Resistojet Electrothermal Thrusters}

Pros: Most spacecraft flight experience of any electric thruster (more than 220 flown). Uses storable fluids that can be serviced off line without the use of a facilitated ground system. Low recurring cost provided the fluid choice is not the toxic $\mathrm{N}_{2} \mathrm{H}_{4}$. Isp $=300 \mathrm{sec}$ with $\mathrm{N}_{2} \mathrm{H}_{4}$ at 500 We.

Cons: Requires high power and has low performance limiting its application. Experience has been mostly with $\mathrm{N}_{2} \mathrm{H}_{4}$, which drives up the life cycle cost.

\subsection{MPD (Magneto-Plasma Dynamic) Electromagnetic Thrusters}

Pros: Uses argon or hydrogen fluid that can be serviced off line with simple system. Provides higher performance than the electrothermal or the electrostatic choices. The thruster has low complexity and thus has the potential for low life cycle cost except that the power requirements are very high and thus the total system cost, when considering the power, power management and distribution and number or size of thrusters required to meet spacecraft thrust size, could override the cost advantages of the simple thruster.

Cons: Very high power requirement. $(>100 \mathrm{kWe})$. Also requires very large vacuum facilities to test on Earth or a demo-flight in space in low earth orbit. This can drive DDT\&E to be very much higher, into the class of a NEP system. High power requirements (e.g. $>100 \mathrm{kWe}$ to $1 \mathrm{MWe}$ ) for larger spacecraft at current $\sim 10-20 \mathrm{~kg} / \mathrm{KWe}$ specific masses drives the power+thrust masses to be very high (e.g. $>10 \mathrm{MT})$

\subsection{Cold Gas Expansion Thrusters}

Pros: Simple, reliable, non-contaminating to the space and spacecraft environment, low cost, and the technology is mature. Fluids considered for this application are $\mathrm{N}_{2}, \mathrm{H}_{2}, \mathrm{NH}_{3}, \mathrm{He}$, and Freon, which are all available. 
Cons: Limited to very low performance (considered heavy and produces low Isp, typically $70 \mathrm{sec}$ for $\mathrm{N}_{2}$ ). Low performance limits the total propellant loading because of the negative impact on the mass ratio of the spacecraft. Consequently, limited to applications only requiring low impulse.

\section{Propulsion Tethers}

4.1 Electrodynamic Tether (EDT) Propulsion

Pros: Application does not use propellant and thus reduces the propellant mass required by spacecraft, This allows the payload to be launched by a smaller launch vehicle - reducing the life cycle cost.

Cons: Application limited to low planetary orbits that have geomagnetic fields to provide power to operate. Application limited to low planetary orbits that have sufficient geomagnetic fields and sufficient ambient ions to conduct the phantom current. Power output for EDT is limited by the flux density of ambient ions. Power density for EDT is a function of geomagnetic field strength (e.g., the EDT would generate enormous power in a small package near Jupiter's intense geomagnetic fields). Power charging back to spacecraft can be an issue and cause shorting out of electrical systems if used in too low an orbit where molecular density is still able to produce static or dynamic discharges. Application is for stationkeeping and slow orbit change, not maneuvering, thus a second propulsion system may still be needed.

\subsection{Momentum Propulsion Tethers}

Pros: Application does not use propellant and thus reduces the propellant mass required by spacecraft, This allows the payload to be launched by a smaller launch vehicle - reducing the life cycle cost.

Cons: Application limited to GEO or high earth orbit. Application is for stationkeeping and slow orbit change, not maneuvering, thus a second propulsion system may still be needed.

\subsection{Electrodynamic Tether / Ion Electrostatic Thruster Hybrid Propulsion}

Combination of Electrodynamic Tether and Ion Electrostatic Thruster.

Pros: Eliminates need for ambient ions and for phantom current path. Power output no longer limited by ambient conditions.

Cons: Power density is a function of geomagnetic field strength. However, this system can utilize the sun's geomagnetic fields which are effective past the orbit of Jupiter.

\section{Propellant and Propulsion}

The next section is propellant and propulsion. This section is presented in four areas. The first area discusses the choice of propellant type such as cryogenic, storable non-toxic and toxic, solids, and hybrids. The second area discusses the choice of propellant by density or performance considerations. This is primarily a discussion of the fuel density improvements of various hydrocarbons versus their performance loss in relation to $\mathrm{H}_{2}$. Mixture ratio shifts and gelled propellant are also discussed. The third area discusses fuel versus oxygen cooling. The fourth area presents monopropellant versus bipropellant system discussions and compares their pros and cons.

\section{Propellant and Propulsion Considerations \\ 1. Choice of Propellant Type \\ 1.1 All Cryogenic}

Pros: Have $\sim 40$ years experience safely handling NBP propellants in support of servicing and flying launch vehicles. Their mass/volume relationship is a function of atmospheric pressure, therefore their flight mass is gauged with a fixed passive measuring system. They provide very high performance.

Cons: The greatest handling concerns for fuels are leaks and potential fires. Therefore, fuel systems require leak free designs (all welded and avoidance of dynamic seals wherever possible) or very tight process verification practices (verify leak tight). Also, $\mathrm{LH}_{2}$ has a very broad flammability and explosive range which requires an operational monitoring and corrective action system to maintain safe operations. Closed compartments are to be avoided by design and, if they 
exist, must be either pressurized or purged to maintain an inert and safe environment. $\mathrm{LO}_{2}$ is impact sensitive with a very small amount of hydrocarbon. Therefore, it requires all surfaces that it might come into contact with be ultra clean. Proper clothing must be used when handling $\mathrm{LO}_{2}$ to avoid cryogenics burns. All small appendages and filters that could contain water vapor or gas contaminants must be removed by purging or evacuation to avoid freezing blockage or chemical contamination. $\mathrm{LO}_{2}$ is of high density and is subject to geysering and water hammer from elevation and dynamics.

\subsection{Storable Non-toxic}

Pros: Most storable propellants have a narrow flammability and explosive range, therefore, making them relatively easy to safely handle. The U.S. energy infrastructure produces large quantities of these propellants and safe storage and handling procedures already exist. Storable fuels have higher densities than $\mathrm{LH}_{2}$ or $\mathrm{LNG}$ and require smaller volume tanks to provide the same mass and require less complex/costly systems to build and operate.

The U.S. has flight experience with RP-1, Alcohol, and $\mathrm{H}_{2} \mathrm{O}_{2}$ fuels.

Cons: These propellants are sensitive to changes in atmospheric conditions. When temperature changes the volume of propellant changes with a resultant propellant density change. Therefore, the temperature must be determined at launch time so that the correct propellant oxidizer to fuel volume ratio is loaded to control the residuals left at the end of flight since the residuals are unusable and considered lost payload. Also most fuels are produced as a mixture of chemical components. They do not have a boiling point, but have a distillation fraction; therefore, a sample must be tested for each launch to determine the proper mass needed for that mission. An alternative to the above practice is to accept the fuel variance and add a flight system that changes the propellant ratio used by the engine to control the residuals. This added system is subject to failure and additional operational maintenance. These propellants are subject to gaining moisture and particles during handling and require moisture removal and conditioning equipment to avoid bacteria growth and contamination. The waste products of this removal process must be properly managed and disposed of which adds cost to the operation. Also these fuel choices produce significantly lower Isp with $\mathrm{O}_{2}$ than $\mathrm{H}_{2}$ does.

\subsection{Storable Toxic}

Pros: These propellants are hypergolic and do not require ignition systems which deletes the need of this support system. They are storable and can be used without concern of losses on long duration space missions.

The U.S. has flight experience with Red Fuming Nitric Acid (IRFNA), Hydrazine, $\mathrm{N}_{2} \mathrm{O}_{4}$, Ammonia $\left(\mathrm{NH}_{3}\right)$, UDMH, Aerozene 50 (50-50 mixture of hydrazine and UDMH), and $\mathrm{MMH}$. The U.S also has ground test experience with FLOX and Fluorine as an oxidizer choice.

Cons: In addition to being a storable propellant and subject to their Con's, the oxidizer leaches out iron from metal containers and handling equipment producing iron nitrate which is a contaminate that blocks filters, small passages and causes moving parts to stick. This contaminant also causes valves to leak. Control of this contaminate requires propellant temperature conditioning and control which produces waste products. The waste products of this removal process must be properly managed and disposed of which adds cost to the operation. The fuel is subject to spontaneous fire with many materials and procedures must be carefully designed to avoid any such contact. Facilities must be designed to control any spills and have corrective systems along with detection systems. This requirement adds considerable cost to the acquisition and operations costs. These toxic propellants require personnel to wear total containment garments to avoid health damage when working with the propellants or intrusively with systems that contain any quantity of these propellants. The entire area must be evacuated and controlled during servicing, maintenance, and launch operations. Personnel working with these propellants must maintain current health records to allow medical personnel to assure their health, which adds another two disciplines at the launch site along with housing, which adds considerable cost to the operation. These systems must use all welded designs to avoid leakage and ground support systems are required to perform clean-up if a spill should occur. These clean-up materials and waste must be disposed of properly and this adds considerable cost. 


\subsection{Solid}

Pros: If the motor is made as a single element, this propulsion system is simpler than the liquid systems and is composed of considerably fewer parts. However, if the desire is reusability, the motor case must be refurbished and refilled every flight as a major logistics function. This is detracting from its lower cost of operation.

Cons: Solid propellant is very expensive to produce. If the solid motor is made up of segments, it requires considerable labor and time to assemble (Shuttle SRM's) and results in a high cost operation. These solid motors are considered very hazardous to handle and require the area to be cleared to both handle them and to arm them with the ignition systems. The facilities also cannot be shared with other functions because of the safety hazard. Safety of flight is also compromised, as the solid motor is not fault tolerant by design. Operationally the solid motor operates very fuel rich; therefore, the ignition overpressure from re-ignition of exhaust or afterburning requires careful consideration to avoid flight vehicle damage during liftoff (Shuttle ignition overpressure suppression system required). Again this drives the operation time and cost to accommodate.

Solid propulsion systems Isp is limited.

\subsection{Hybrid Solid Fuel/Self Pressurizing Oxidizer}

Pros: This choice is considerably safer than solid propulsion system because the solid fuel is inert and safe to handle. The self-pressurizing oxidizer is safe to handle, relatively easy to service, and does not require flight support systems to function. This choice would be much less costly versus the solid motor to procure and use operationally. Concept provides fault tolerance and can be terminated or re-started.

Cons: Reusability of the solid fuel motor would require refurbishment and reload off line. This will require time and manpower to perform driving up the recurring cost. Therefore, option seems best suited to an expendable upper stage application. Again this choice is very limited in its Isp/performance. This choice has no known flight experience, but small-scale tests are being conducted at the UAH Propulsion Research Center.

\subsection{Hybrid Solid Fuel/Pump Fed Oxidizer}

Pros: This choice has the same advantages as the above hybrid except the pump fed oxidizer has considerably more parts and support systems. The result is higher Isp than the hybrid above.

Cons: This choice has the same drawbacks as the option above plus considerably more parts and support systems. This choice has extensive ground test, but only small-scale flight experience. Also this option has some safety concerns for $\mathrm{LO}_{2}$ compatibility with the fuel during ground servicing operation. 


\section{Choice of Propellant by Density or Performance Considerations}

A quick overview of the relative comparison of hydrocarbon fuel versus hydrogen, some with oxygen, hydrogen peroxide, and nitrogen tetraoxide as the oxidizer, is shown below.
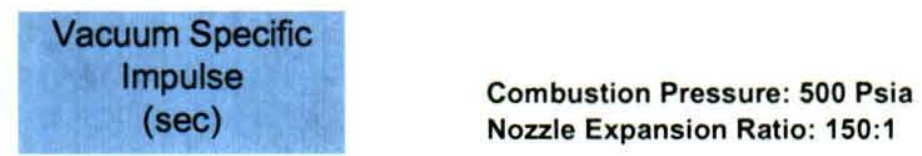

Nozzle Expansion Ratio: 150:1
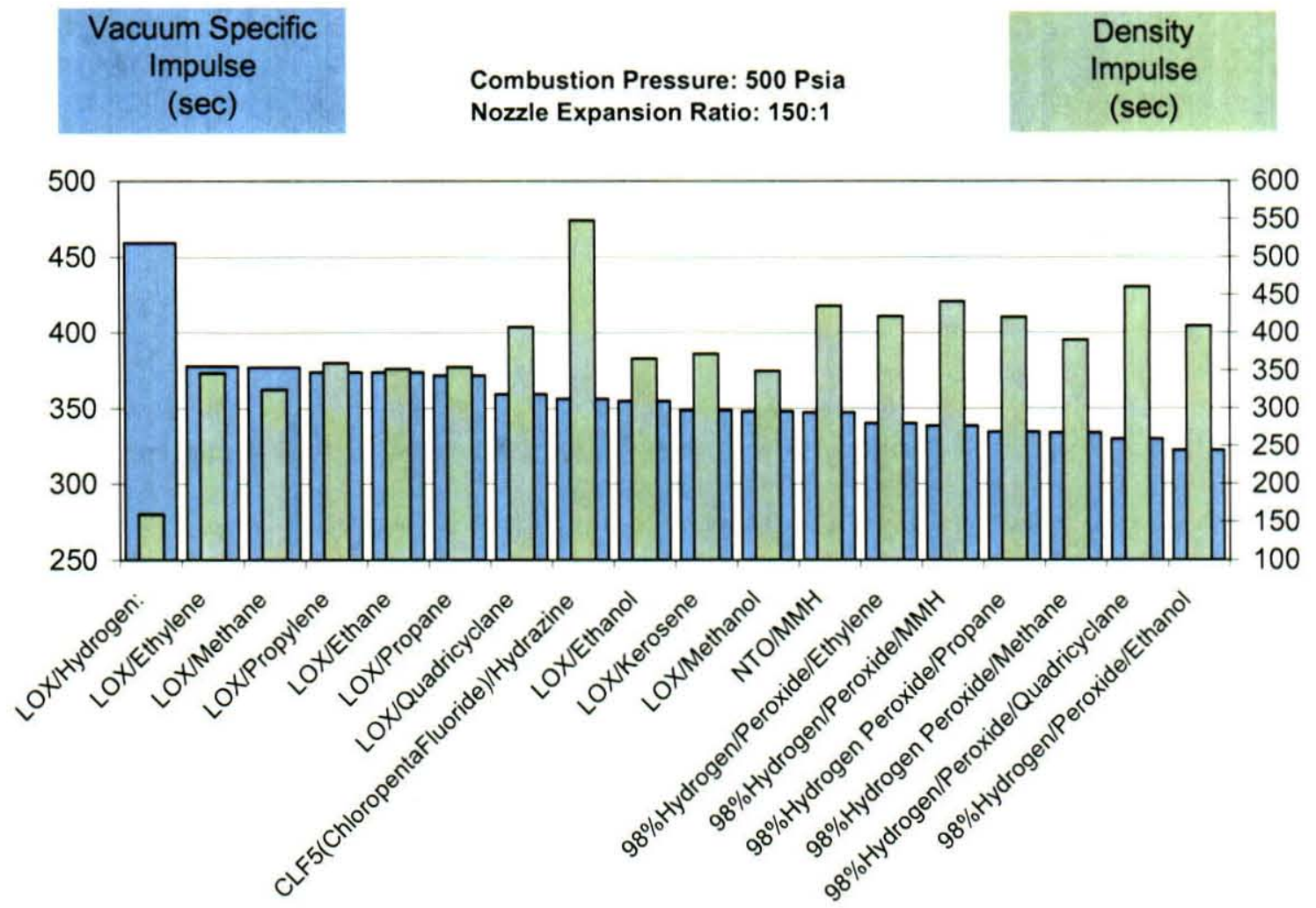

\subsection{Liquid Hydrogen (NBP)}

Pros: Have $\sim 40$ years experience safely handling NBP $\mathrm{LH}_{2}$ in support of servicing and flying launch vehicles. Its mass/volume relationship is a function of atmospheric pressure, therefore its flight mass is gauged with a fixed passive measuring system. It is a very high performance fuel. In the event of a large spill the hydrogen evaporates very rapidly and rises, thus reducing the potential of a very large ground level explosion provided it isn't collected in an entrapment.

Cons: Greatest handling concern is leaks and potential fires. Therefore, fuel systems require leak free designs (all welded and avoidance of dynamic seals wherever possible) or very tight process verification practices (verify leak tight). Also, $\mathrm{LH}_{2}$ has a very broad flammability and explosive range which requires an operational monitoring and corrective action system to maintain safe operations. Closed compartments are to be avoided by design and, if they exist, must be either pressurized or purged to maintain an inert and safe environment.

\subsection{Densified Hydrogen (Triple Point)}

Pros: Increases the density of the tanked hydrogen. Perceived as a performance gain as the vehicle tank volume is less, but will require an added cold helium bubbling system, submerged in the $\mathrm{LH}_{2}$ tank, for safety during ground servicing to maintain tank positive pressure.

Cons: Requires a considerable addition of ground support systems, e.g., added helium chiller and pressurization system, that must be active to maintain safe control of the vehicle $\mathrm{LH}_{2}$ tank. Requires support systems for the $\mathrm{LH}_{2}$ hydrogen densifier. Will result in large additional recurring cost in propellants and gases. Handling $\mathrm{LH}_{2}$ below the normal boiling point adds considerable 


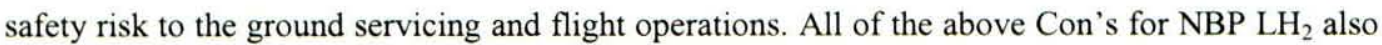
apply to the densified hydrogen concept.

\subsection{RP-1}

Pros: RP-1 is a storable propellant and has a narrow flammability and explosive range, therefore, making it somewhat easier to safely handle compared to liquid hydrogen. However, the safety issues of RP-1 should not be under estimated as it has a low flash point and will gel with $\mathrm{LO}_{2}$ in the event of a combined spill. It therefore has a large explosive potential. The U.S. energy infrastructure produces large quantities of these propellants and safe storage and handling procedures already exist. Storable fuels have higher densities than $\mathrm{LH}_{2}$ or LNG and require smaller volume tanks to provide the same mass and require less complex/costly systems to build and operate.

Cons: This propellant is sensitive to changes in atmospheric conditions. When temperature changes the volume of the propellant changes with a resultant propellant density change. Therefore, the temperature must be determined at launch time so that the correct propellant oxidizer to fuel volume ratio is loaded to control the residuals left at the end of flight since the residuals are un-usable and considered lost payload. Also kerosene is produced as a mixture of chemical components. It does not have a boiling point, but has a distillation fraction; therefore, a sample must be tested for each launch to determine the proper mass needed for that mission. An alternative to the above practice is to accept the fuel variance and add a flight system that changes the propellant ratio used by the engine to control the residuals. This added system is subject to failure and additional operational maintenance. Kerosene is subject to gaining moisture and particles during handling and requires moisture removal and conditioning equipment to avoid bacteria growth and contamination. The waste products of this removal process must be properly managed and disposed of which adds cost to the operation. Also these fuel choices produce significantly lower Isp with $\mathrm{O}_{2}$ than $\mathrm{H}_{2}$ does. Some designs condition or heat the RP-1 to reduce the GLOW of the vehicle as well as the residual mass, and this conditioning ground system adds complexity and cost. RP-1 does not evaporate like hydrogen and leaves a film and deposits that must be cleaned for reusable systems to avoid reaction with Lox.

\subsection{Methane}

Pros: Propellant is less expensive to procure and is denser than $\mathrm{LH}_{2}$. Propellant is more available throughout the U.S. It delivers a higher Isp than RP-1. Unlike RP-1, methane does evaporate like hydrogen.

Cons: Delivers less performance than $\mathrm{LH}_{2}$. There is no flight experience with this propellant.

\subsection{Propane}

Pros: Propellant is less expensive to procure and is denser than $\mathrm{LH}_{2}$. Propellant is more available throughout the U.S. It delivers a higher Isp than RP-1. Unlike RP-1, propane does evaporate like hydrogen.

Cons: Delivers less performance than $\mathrm{LH}_{2}$. There is no flight experience with this propellant. Propellant is more dense than air and will accumulate if leaked causing a potential fire/explosion hazard.

\subsection{Shift Mixture Ratio to Oxygen Rich for Sea-Leval and Low Altitude Operation}

Pros: This choice will provide mass fraction gains for the flight vehicle and the Russians have used these combustion techniques satisfactorily. Will provide higher thrust at sea level operation when most needed and then shift to preferred fuel rich for Isp gains when thrust is no longer the driver. May allow performance gains such that SSTO can be obtained or could reduce the ground infrastructure to one less fuel to provide considerable cost reduction.

Cons: The U.S. does not have any experience flying systems that use this choice today. Oxygen rich combustion increases the heat flux in the combustion chamber and the nozzle from the increased mass flow. Therefore, the cooling capacity must also be increased to accommodate this mode of operation. This choice may be better suited to also using oxygen cooling instead of fuel. 


\subsection{Gelled Propellants}

Pros: Thixotropic gels have gained interest because of their characteristic to tolerate small tank penetrations while in use providing a degree of greater fault tolerance than liquid propellants. This characteristic suggests this choice may be suited for in-space long life applications because of concerns of space debris. There have been some missile tests with MMH and IRFNA gels as well as ground testing of gelled propellant for crew escape systems. Some gels have demonstrated the ability to be stored at a frozen state and warm to ambient conditions and then fired. Gelation improves handling and storage and helps alleviate the toxicity issues of some gels (e.g. MMH, IRFNA) by lowering the vapor pressure and the surface area of a potential spill.

Cons: There is no space flight experience with gels. Gelation may improve some aspects of handling and storage, but they do not eliminate the inherent safety and toxicity problems with these very toxic propellants. When considering the use of gelled propellants there are many remaining concerns with the long-term storage and fluid dynamics of their feed systems as well as the reusability of systems. Reusability and life cost have not been addressed in past design efforts or testing and would be as high as standard liquid systems.

\section{Choice of Rocket Engine Combustion Chamber/Nozzle Cooling \\ 3.1 Fuel Cooled}

Pros: Fuel cooling is the common practice for all U.S. designs when using liquid oxygen as the oxidizer and is well understood. Avoids safety concern for engine hardware burn-through.

Cons: If the fuel choice is a hydrocarbon, the engine components must be filled and bled from the main fuel valve aft or the system must be evacuated from the fuel pre-valves aft prior to engine start and fuel dropped during the start sequence as the Russian's do. In either case the concern for fuel leakage past the main fuel vale is time critical and may require the systems downstream of both main valves be cleaning solvent-flushed to avoid engine explosion during the start sequence. Also the shutdown sequence will cause fuel coking in the engine. If the engine is reusable his will require a cleaning process after each mission and an added recurring cost. If the fuel choice is cryogenic $\mathrm{LH}_{2}$, the start sequence requires a fuel lead for cooling and this excess fuel during both startup and shutdown causes safety concerns and possible damaging overpressure. To avoid this concern, a burn-off system is needed that is critical and adds considerable cost to the operation. Excess fuel during shutdown is also a concern because if there are any entrapments, this could cause an explosion.

\subsection{Oxygen Cooled}

Pros: Removes the concern for coking during shutdown using hydrocarbon fuels and deletes the concern for ignition overpressure during startup with cryogenic fuels. Also removes the concern for fuel entrapment resulting in potential explosions during engine shutdowns or aborts when using cryogenic fuels. These above hardware avoidances improve safety, increase system responsiveness, and lower life cycle cost.

Cons: No experience in the U.S. using this design choice except when using hypergolic propellants where it is the common choice. Hardware burn-through failure mode criticality is largest reason not to attempt this design approach; however, feasibility testing of this approach has been accomplished with both $\mathrm{LH}_{2}$ and RP-1 fuels with no detrimental effects. In fact slots were cut in the cooling passages inside the combustion chamber to simulate this burn-through leakage without any detrimental effects. For $\mathrm{O}_{2} / \mathrm{H}_{2}$ engines, the constant pressure specific heat of $\mathrm{H}_{2}$ is about nine times better than $\mathrm{O}_{2}$. So it takes about nine times the mass of $\mathrm{O}_{2}$ through the same temperature range to match the $\mathrm{H}_{2}$ cooling. $\mathrm{H}_{2}$ and the hydrocarbon fuel can be raised to a high bulk temperature in the cooling circuits. On the other hand, it is unknown to what temperature $\mathrm{O}_{2}$ can be safely raised and the only test data, from the 1970's, was for a bulk temperature below room temperature. Consequently, it is expected that the temperature rise of $\mathrm{O}_{2}$ cooling will be limited in comparison to $\mathrm{H}_{2}$ and the hydrocarbon fuels.

\section{Monopropellant versus Bipropellant Systems \\ 4.1 Tridyne}

Pros: This propellant is produced off-line and is contained in a single container on the vehicle. A small amount of a stoichiometric mixture of $\mathrm{GO}_{2}$ and $\mathrm{GH}_{2}$ is added to helium or to nitrogen to 
provide a non-flammable mixture. This propellant can be treated like a monopropellant. It requires a catalytic device to provide auto-combustion and therefore does not require a separate ignition system. Tridyne is normally stored at high pressure. It is an extremely safe and inert system. Produces a reduction in ground support systems required for servicing and the total parts count on the vehicle is reduced providing greater reliability.

Cons: Requires an off-line ground facility to produce the gas mixture.

\subsection{Cold Gas}

Pros: These monopropellant systems provide minimum vehicle interface servicing and are composed of a minimum number of parts, which results in lower life/cycle cost. They are safe and inert. The technology is proven and mature.

Cons: These propulsion systems provide low performance.

\subsection{Hydrogen Peroxide}

Pros: This monopropellant system provides minimum vehicle interface servicing and is composed of a minimum number of parts, which results in lower life/cycle cost. This choice doesn't require combustion as it uses a catalytic device to provide decomposition and gas expansion for propulsion.

Cons: This propulsion system provides low performance. High purity hydrogen peroxide is very sensitive to contamination and requires that any surfaces that come into contact with it to be ultraclean. The contaminate imitates the decomposition process which builds pressure that can get out of control very rapidly and result in an explosion. Therefore, safe operating practices for new hardware suggests the system be exposed to a dilute product (35\% or less) to assure system is clean and safe before filling with propellant. This propellant is also considered somewhat unstable and can go bad (out of specification/purity) just sitting in the shipping container.

\subsection{Hydroxyl Ammonium Nitrate (HAN)}

Pros: This monopropellant system provides minimum vehicle interface servicing and is composed of a minimum number of parts, which results in lower life/cycle cost. This choice doesn't require combustion as it uses a catalytic device to provide decomposition and gas expansion for propulsion. Much safer than hydrazine because it is non-toxic.

Cons: Performance may be slightly lower than hydrazine. Fluid is corrosive and causes material compatibility concerns. Also may require heat to get the catalytic reaction started. No flight test experience.

\subsection{Hydrazine}

Pros: The space community has considerable experience using this monopropellant and safety practices are established. Since it is a monopropellant, the interfaces are less than a bi-propellant which allows servicing with less equipment than a toxic bi-propellant system. This choice doesn't require combustion as it uses a catalytic device to provide decomposition and gas expansion for propulsion.

Cons: This monopropellant choice provides low propulsion performance. The fuel is subject to spontaneous fire with many materials and procedures must be carefully designed to avoid any such contact. Facilities must be designed to control any spills and have corrective systems along with detection systems. This requirement adds considerable cost to the acquisition and operations costs. These toxic propellants require personnel to ware total containment garments to avoid health damage when working with the propellants or intrusively with systems that contain any quantity of these propellants. The entire area must be evacuated and controlled during servicing, maintenance, and launch operations. Personnel working with these propellants must maintain current health records to allow medical personnel to assure their health, which adds another two disciplines at the launch site along with housing, which adds considerable cost to the operation. These systems must use all welded designs to avoid leakage and ground support systems are required to perform clean-up if a spill should occur. These clean-up materials and waste must be disposed of properly and this adds considerable cost. 


\subsection{Nitrous Oxide $\left(\mathrm{N}_{2} \mathrm{O}_{2}\right)$}

Pros: Propellant is a self-pressurizing oxidizer and is safe to handle, relatively easy to service, and does not require flight support systems to function. Ground handling and servicing of flight system will be much simpler. Propellant choice is much safer to use because it is non-toxic. Propellant can be use as a bi-propellant with a fuel or as a monopropellant with a catalyst. The catalyst requires heat to get the reaction started.

Cons: Can be used in place of hydrazine, but may yield slightly less performance. Density is less than $\mathrm{LO}_{2}$. And will therefore require greater flight storage volume. When used as a monopropellant, the catalyst requires heat to get the reaction started.

\section{7 $\mathrm{LO}_{2} / \mathrm{LH}_{2}$}

Pros: Have considerable years of experience successfully using this propellant combination. This is a very high performance option, which provides the greatest opportunity to reduce the total number of stages for a given application. The result is a large life cycle cost reduction (less flight hardware and very large reduction in support infrastructure and ground support equipment). This choice has the Pro's listed for "1.1 All Cryogenic".

Cons: This choice has the entire Con's listed for "1.1 All Cryogenic".

\section{8 $\mathrm{LO}_{2} / \mathrm{RP}-1$}

Pros: Have considerable years of experience successfully using this propellant combination. Performance is less than $\mathrm{LO}_{2} / \mathrm{LH}_{2}$ option, but provides greater thrust performance during early part of flight. This choice has the Pro's listed for 1.1 All Cryogenics for the oxidizer choice and the Pro's listed for the 2.3 RP-1 fuel choice.

Cons: This choice has all the Con's listed for 1.1 All Cryogenic that are related to the oxidizer only and the entire Con's listed with storable 2.3 RP-1 choice.

\section{9 $\mathrm{LO}_{2} /$ Methane}

Pros: If the intent is to provide reusable engines and the coolant is by fuel, methane is less sensitive to coking than other hydrocarbon fuels. Fuel is denser than $\mathrm{LH}_{2}$ and requires less flight storage volume.

Cons: Fuel choice will yield less performance than $\mathrm{LH}_{2}$. No experience in using as a space flight propellant.

\subsection{0 $\mathrm{LO}_{2} /$ Propane}

Pros: If the intent is to provide reusable engines and the coolant is by fuel, methane is less sensitive to coking than other hydrocarbon fuels. Fuel is denser than $\mathrm{LH}_{2}$ and requires less flight storage volume.

Cons: Fuel choice will yield less performance than $\mathrm{LH}_{2}$. No experience in using as a space flight propellant.

\subsection{Hypergolic}

Pros: Hypergolic propellants do not require ignition systems, therefore deleting the need of an ignition support system. They are storable and can be used without concern of losses on long duration space missions. These propellants provide reasonably high Isp for a storable propellant.

Cons: In addition to being a storable propellant and subject to their Con's, the oxidizer leaches out iron from metal containers and handling equipment producing iron nitrate which is a contaminate that blocks filters, small passages and causes moving parts to stick. This contaminant also causes valves to leak. Control of this contaminate requires propellant temperature conditioning and control which produces waste products. The waste products of this removal process must be properly managed and disposed of which adds cost to the operation. The fuel is subject to spontaneous fire with many materials and procedures must be carefully designed to avoid any such contact. Facilities must be designed to control any spills and have corrective systems along with detection systems. This requirement adds considerable cost to the acquisition and operations costs. These toxic propellants require personnel to ware total containment garments to avoid health damage when working with the propellants or intrusively with systems that contain any quantity of these propellants. The entire area must be evacuated and controlled during servicing, 
maintenance, and launch operations. Personnel working with these propellants must maintain current health records to allow medical personnel to assure their health, which adds another two disciplines at the launch site along with housing, which adds considerable cost to the operation. These systems must use all welded designs to avoid leakage and ground support systems are required to perform clean-up if a spill should occur. These clean-up materials and waste must be disposed of properly and this adds considerable cost.

\section{Functional Integration}

The next section is functional integration. This section is presented in four areas. The first area, rocket combustion cycle choice, discusses engine power cycle choices. The second area, choice of vehicle guidance and control steering (ETO), discusses the various methods for thrust vector control for an earth-to-orbit stage. The third area, choice of vehicle guidance and control steering (in-space), discusses two choices for steering for an in-space stage. The last area, integrating propulsion, power, and thermal management functions versus using stand alone systems, discusses various levels of integrating propulsion, power, and thermal control.

\section{Functional Integration Considerations}

\section{Rocket Combustion Cycle Choice}

All engine power cycles are either "open" or "closed". In an "open" cycle the fluid that powers the turbine is dumped overboard in its own nozzle or in the thrust chamber assembly downstream of the throat at lower than main chamber pressure. In a "closed" cycle the fluid that powers the turbine is injected into the main combustion chamber at the main chamber pressure after powering the turbine. For example, a gas generator cycle is an open cycle and a fuel-rich staged combustion cycle is a closed cycle.

The energy to power the turbine comes either from regenerative cooling of the engine (or latent heat of the hardware for starting) or from burning some or all of the propellants. The cycles that rely on regenerative cooling are called expander cycles. The cycles that rely on burning propellants are called gas generator cycles if they are open cycles, or staged combustion cycles if they are closed cycles.

Engine power cycles can be implemented differently on the fuel side than on the oxidizer side. The entire engine does not have to use only one power cycle. An example would be an engine that uses an open expander on the fuel side and a gas generator on the oxidizer side.

For the same chamber pressure and area ratio, the two closed cycles, expander and staged combustion, will have higher specific impulse than the open cycle (gas generator). The staged combustion cycle can reach higher chamber pressures (and thus higher area ratios for the same envelope) than the expander cycle and thus can reach a higher specific impulse.

For the same chamber pressure and area ratio, the expander will have the highest engine thrust-toweight ratio, the gas generator will be poorer, and the staged combustion cycle will be the poorest. However, the gas generator and the staged combustion cycles can reach higher chamber pressures which, depending on the value of the chamber pressure, may allow them to exceed the expander thrust-to-weight ratio for the same area ratio.

\subsection{Staged Combustion Cycle Driven by Performance Efficiency}

Staged combustion power cycles can be fuel-rich, oxidizer-rich, or full flow (fuel-rich on the fuel side and oxidizer-rich on the oxidizer side). They are all closed cycles.

Pros: This is the only reusable cycle that has flight experience. This cycle develops a high efficiency combustion process, and has higher specific impulse than the gas generator cycle. The Shuttle SSME uses this cycle and there is considerable experience with it. The Russians have used this cycle extensively, however, only for expendable applications.

Cons: Because the staged combustion cycle must operate at higher internal pressures than the gas generator to achieve the same chamber pressure, it is more complex than the gas generator cycle. 
The staged combustion cycle has much more extreme internal pressure environments than the other two cycles.

\subsection{Expander Cycle Driven by Long Life/Dependability}

Expander power cycles can use the fuel or the oxidizer, or they can use both propellants. They can be open cycles, closed cycles, or mixed.

Pros: Because the expander cycle has no gas generator or precombustor, with their associated plumbing and ignition systems, expander cycles have less hardware and are less complex than the gas generator or staged combustion cycles. Turbine temperatures are generally lower than the other cycles. The lower turbine temperatures make the cycle more robust than the other cycles and the lower turbine temperature and the decreased complexity increases the cycle dependability compared to the other cycles. For the above reasons the expected recurring cost would be lower and the resulting responsiveness would also be higher. There is extensive flight experience with this power cycle, all for upper stage applications. Several versions are in production and in flight today (e.g. RL10A, RL10B, LE-5B, VINCI, RD-0146) that use the closed expander or open expander cycles with hydrogen fuel. Typical missions use 2 to 3 re-starts for each flight and 6 restarts for orbital maneuvering has been demonstrated. The cycle has potential for using other fuels such as liquid methane although at lower performance than the liquid hydrogen flown today.

Cons: This cycle has not been used on a reusable engine and has only been demonstrated at thrust levels suitable for upper stage engines. Because the engine cycle uses heat exchange from a fluid as it is warmed, and possibly gasified, the thrust size limited. The limit occurs because the surface area available to regeneratively cool does not increase linearly with the thrust. The expander cycle also is limited to lower chamber pressures, at a given thrust, than the other cycles because it can only use regeneratively recovered heat. It cannot add heat from precombusting the propellants. Thus the scale-up ability of this cycle is limited to creative ways of obtaining the required heat to drive the cycle.

\subsection{Gas Generator Cycle Driven by Simplicity and Size Flexibility}

Gas generator power cycles can be fuel-rich or oxidizer-rich. They are all open cycles.

Pros: There is a large experience base using this cycle. To date all the applications have been expendable. This choice is less complex than the staged combustion cycle and more complex than the expander cycle. Because the cycle is open, the turbine/turbopump system can be tested independently as a "power-pack" before integrating with the main combustion chamber, thus reducing development risk.

Cons: This cycle is not as efficient as the staged combustion cycle or the expander cycle and will produce a lower specific impulse. The internal pressure environments are higher than those in the expander cycle and lower than those in the staged combustion cycle. The internal temperature environments are generally the highest of the three cycles in an attempt to minimize the turbine flowrate and thus the specific impulse loss.

\subsection{Tap-Off Cycle}

The Tap-off cycle is a gas generator cycle without a separate gas generator. Instead fluid is "tapped-off" from the combustion chamber to drive the turbines.

Pros: The gas generator and its associated propellant feed plumbing are eliminated. This cycle was developed and extensively tested on the J-2S program (six engines and $>21,000$ seconds of mainstage testing).

Cons: Potential erosion of tap-off ports is a concern. No flight experience with this cycle.

\subsection{Pulse Detonation Combustion}

A pulsed detonation engine uses the detonation process to increase the chamber pressure instead of using pumps.

Pros: The lack of turbopumps produces an engine with less hardware and a higher thrust to weight ratio. The detonation process also produces a higher theoretical specific impulse which should allow a higher delivered performance.

Cons: No flight experience. The engine is pulsed and not continuous which may limit the range of applications. The pulsed pressure cycles produce a dynamic demand on the propellant supply 
valves and the injector environment causing concern for reliability/dependability and long life for use in a reusable system application. Combustion noise may become a concern with this choice if used for sea level take-off with a large thrust size (e.g. > 50,000-pounds).

\section{Choice of Vehicle Guidance and Control Steering (ETO)}

2.1 Thrust Vector Control by Gimbaling Rocket Nozzles (TVC)

Pros: Extensive experience exists with this choice, both on expendable vehicles and on the reusable STS. This approach is simple, proven, and mature. Produces a 90 degree force component with a long moment arm thus allowing small forces to be used (small gimbal angles needed). Net effect is only a small thrust loss. Allows thrust vectoring with a single engine.

Cons: Because the entire engine angulates, all lines that go from the vehicle to the engine must have flex joints in them. This adds weight and complexity. The high inertia of the engine coupled with high slew rates requires high power. Current engines use hydraulic actuators which have had significant maintenance problems for the STS (see 2.2 below).

\subsection{Actuation of Thrust Vector Control by Gimbaling - Distributed Hydraulic Actuators}

Pros: Much experience exists with this choice, both on expendable vehicles and on the reusable STS. Hydraulic system weights are reasonably insensitive to the amount of force needed.

Cons: Distributed hydraulic systems have generated an entire infrastructure including GSE and launch support maintenance. Distributed hydraulic systems have leakage and contamination issues that require additional maintenance. The hydraulic actuators require periodic overhaul for reusable systems. Besides imposing a very large requirement on support systems, the use of a distributed hydraulic actuator system results in many additional parts required by the hydraulic system to provide actuator forces. The criticality of these support systems exacerbates this problem. This approach traditionally has generated a large amount of work content between flights and requires extensive servicing. All of these factors drive up the life cycle cost considerably.

\subsection{Actuation of Thrust Vector Control by Gimbaling - Electro-Hydraulic Actuators}

Pros: Eliminates distributed hydraulic system. Eliminates the need for large amounts of power versus using EMAs. The hydraulic package is a compact line replaceable unit.

Cons: No flight experience. For large engines, heavier than distributed hydraulics (lighter than EMAs).

\subsection{Actuation of Thrust Vector Control by Gimbaling - Electromachanical Actuators (EMAs)}

Pros: A switch to electrical actuators has the potential for reducing cost, complexity, maintenance, and LCC.

Cons: The weight of the power generation equipment may be excessive for large thrust engines at high slew rates.

\subsection{Jet and Air Vanes}

Pros: This choice was used on early designs and is reasonably robust, but the jet vanes are not reusable and would require replacement between each flight. Would result in lower life cycle cost compared to the traditional TVC approach for expendable systems. Allows thrust vectoring with a single engine.

Cons: This choice seems to be applicable to only small vehicle designs.

\subsection{Nozzle Injection System}

Pros: This choice allows the rocket nozzle to be fixed, which simplifies it (no flex joint in the nozzle to motor design). This choice has been used on solid motor designs and should be restricted to this application. Deletes the requirement for an actuating/gimbaling system, which reduces a large number of parts. This should increase the reliability of the system and reduce the servicing requirements. Should result in lowering the life cycle cost. Allows thrust vectoring with a single engine.

Cons: The amount of fluid can be significant (above $10 \%$ of nozzle flow) for large equivalent gimbal angles. This approach requires a separate set of injection hardware, tankage for the injected fluid, and a pressurant system for the fluid. If the engine is reusable, then these added systems 
would require servicing between each flight. This drives up the life cycle cost and reduces the Safety/reliability. Therefore, the choice is very sensitivity to the actual design and requires a trade study of each design choice before selection.

\subsection{Differential Throttling of Rocket Nozzles}

Pros: This choice eliminates the need to gimbal, providing a large reduction in support systems and total parts. This should result in increased reliability, and lower life cycle cost. Results in a ground support infrastructure reduction, and lower life cycle cost. Multiple engines providing the nominal thrust may provide engine out capability increasing mission reliability.

Cons: This approach only works in an installation having at least three engines. It works with less penalty as more engines are included. There is less control authority with this approach than with gimballing. The engines must be designed for a thrust level significantly above the nominal thrust which will increase the engine weight for the nominal thrust. This choice places an active roll on throttling the engines to achieve the vehicle flight control. The throttling must be continuous (not stepped) and must be capable of dwelling for long periods at any throttle setting. These characteristics impose severe requirements on the valves, their actuators, and the turbopump dynamic design. This choice has not been used and there is no experience to date. This choice will dictate the minimum number and placement of rocket nozzles.

\section{Choice of Vehicle Guidance and Control Steering (In-Space)}

\subsection{Thrust Vector Control by Gimbaling Nozzles (TVC)}

Pros: Considerable experience exists with this choice with the reusable STS OMS electromechanical TVC.

Cons: Will not provide 3-axis control in space and is much more difficult to control the impulse magnitudes.

\subsection{Reaction Control with Dedicated Thrusters}

Pros: Provides great maneuverability in all three axis and can provide both course and fine adjustments. Propulsion choices will allow selection of non-contamination solution when environment dictates.

Cons: Requires significant hardware and additional sub-systems driving reliability/dependability down and the maintenance requirements up. Produces increased life cycle cost and an increased ground infrastructure.

\section{Integrating Propulsion, Power, and Thermal Management Functions versus Using Stand Alone} Systems

\subsection{Turbo-Alternator Driven From an Autogenous Tank Pressurization System}

Pros: Where the system design uses an autogenous propellant tank pressurization system (e.g., the STS), a turbo-alternator can be used, adding a very small amount of weight, without any additional performance loss. This choice will provide power during ascent enabling electromechanical device application versus hydraulic systems resulting in a large reduction of vehicle support systems and their ground infrastructure. This choice will add reliability, increase safety, and reduce life cycle cost.

Cons: Requires a flight qualified dependable turbo-alternator for design selection. This choice only provides power during ascent phase of flight.

\subsection{Main Propellant from Common Tanks Feeding Fuel Cell Power System}

Pros: In a reusable transportation system the residual propellant tank gases can be used for supply of the fuel cell power system with the aid of a small low-pressure gas compressor. This approach would reduce system hardware and result in increased reliability and lower life cycle cost. If the system is reusable the ground servicing time for the fuel cell between flights will be significantly reduced.

Cons: Present fuel cells used on STS cannot use propellant grade oxygen; however, future designs will be compatible. There is no flight experience with these new fuel cells. Designers are comfortable with the current approach. 


\subsection{In-Space Control System (RCS) and Main Engines Fed from Common Propellant Tanks}

Pros: This choice will delete several stand-alone flight propellant and pressurant tanks. Concept will also delete ground and flight servicing hardware for all of these stand-alone vessels. Will result in a very large support infrastructure reduction, both at the launch site and for manufacturing/sustaining engineering. This reduction of systems will result in a large part count reduction and add reliability, increase safety, and reduce life cycle cost. This approach may lend itself to enabling the use of presently un-usable propellant following the ascent phase of flight. If the system is reusable, the ground servicing time for the RCS function between flights will be significantly reduced.

Cons: If choice is to use liquid propellant for the RCS function, there will be a need for a propellant management system for the zero-g environment. There is no experience in this approach with reusable space vehicles.

\subsection{In-Space Orbital Maneuvering Propulsion System and/or RCS System and/or Main Engines Fed from Common Propellant Tanks}

Pros: This choice will delete several stand-alone flight propellant and pressurant tanks. Concept will also delete ground and flight servicing hardware for all of these stand-alone vessels. Will result in a very large support infrastructure reduction, both at the launch site and for manufacturing/sustaining engineering. This reduction of systems will result in a large part count reduction and add reliability, increase safety, and reduce life cycle cost. This approach may lend itself to enabling the use of presently un-usable propellant following the ascent phase of flight. If the system is reusable, the ground servicing time for the OMS function between flights will be significantly reduced.

Cons: If choice is to use liquid propellant for the OMS function, there will be a need for a propellant management system for the zero-g environment. There is no experience in this approach with reusable space vehicles.

\subsection{Active Thermal Management System Fed from Common Propellant Tank Fluid}

Pros: Choice will delete dedicated ground servicing systems for support of this function and the vehicle interface hardware. Will result in a support infrastructure, both at the launch site and for manufacturing/sustaining engineering, reduction. This choice will add reliability, increase safety, and reduce life cycle cost. The ground servicing time for the active thermal management function between flights will be significantly reduced.

Cons: If choice is to use liquid propellant for this thermal management function, there will be a need for a propellant management system for the zero-g environment. There is no experience in this approach with reusable space vehicles. If electrical hardware requires active cooling as in the STS, the benefit will be reduced considerably.

Any of the common or fully integrated systems that are considered to permit greater synergy of the overall system energy management comes at a price. Redundancy is a requirements and modularity of the systems needs to be considered so that components of the common/integrated system can be changed out if they fail without impacting the other elements of the integrated system. Reliability can be lower since there can be more elements to maintain.

\section{Thermal Management}

The next section is thermal management. There are only two areas in this section. The first area, integral propellant tank and structure versus tank and aero-shell, discusses two approaches to structure and their impacts on thermal management. The second area, cryogenic tank thermo-insulation considerations, discusses tree approaches to tank insulation for ascent and re-entry. 


\section{E. Thermal Management Considerations}

1. Integral Propellant Tank and Structure versus Tank and Aero-Shell

\subsection{Traditional Integral Tank/Structure}

Pros: Main propulsion tank/integral structural choice used on STS, but as an expendable design. This choice eliminates the safety requirement to monitor and control by purge the entrapped areas caused by separate tank and shell design. Therefore this choice eliminates safety systems that results in higher system safety and lower life cycle cost. Results in a lighter overall design solution for increased performance while also resulting in the lowest life cycle cost option.

Cons: To support the reusable design approach the tank skin must accommodate the propellant temperatures and the re-entry heating environment. These requirements pose a challenge to the designer when not allowing a purge system to be a part of the solution.

\subsection{Wing Tanks/Aero Shell for Vehicle Lift}

Pros: Would accommodate change out of tanks when needed for the reusable concept. Reduces the sensitivity of balancing the thermal environments of the propellant and the re-entry heating.

Cons: Adds requirement for safety monitoring system and safety control systems for both explosive potential and for personnel maintenance when required. Added support systems lower the reliability and safety, and add large ground infrastructure support. These all result in increased life cycle cost. Also this results in the functional verification requirement of thermal insulation parameters between flights. Performance may be less with this choice, as the dry weight will most likely increase.

\section{Cryogenic Tank Thermo-Insulation Considerations}

2.1 Internal Tank Insulation for Cryogenics Thermal Control and External Insulation for Re-entry Heating Structural Control

Pros: Provided the design is margin-robust, this choice provides simple passive approach to a complex design concern. With a minimum quantity of IVHM, this choice should result is a low life cycle cost solution.

Cons: Unless the design technology is very mature, the internal insulation could require excessive maintenance. Have experience with internal insulation for the expendable application (SIV \& SIVB stages of Saturn vehicle).

\subsection{Complex Purged Composite Insulation for Total Heat Transfer Control}

Pros: Design may produce the lightest weight design. Total insulation external of the structural substrate which should reduce the need for tank entry.

Cons: This choice will require an added flight support system (GHe purge system like Centaur) and its ground support infrastructure driving up the life cycle cost. There is no experience with this choice for reusable applications. IVHM for this concept is also unclear.

\subsection{Internal Tank Insulation for Cryogenics Thermal Control and External Insulations System} that Recovers Useful Heat Energy for Integrated Functional use while Providing Protection from Re-entry Heating

Pros: Has the same Pro's as the first choice plus the added energy gained during re-entry may allow deletion or simplification of other flight systems contributing to a lower cost life cycle cost approach.

Cons: Has the same Con's as the first choice plus there is no experience nor are there any design concepts with this heat recovery approach.

\section{Conclusions}

The first order effects of a number of propulsion system and related subsystem choices have been presented to help users assess the preliminary impact of these choices on architectures. A review of these general space launch vehicle, spacecraft propulsion, thermal, and power related subsystem attributes should be performed when conceptualizing any new or derivative system. Also, the Technology Readiness Level (the measure of design 
maturity) and the design risk (in cost and schedule) must be carefully considered for each design choice and approach.

Then the actual selection of various subsystem elements and approaches must be optimized at the overall systems level using a tool that allows focus on multiple attributes and not only one attribute (such as, engine specific performance or weight). Otherwise the engine may be optimized, but at the expense of the system.

Reviewing this "design-guide" and implementing the optimum set of systems will lead to a space launch vehicle or spacecraft with the optimum combination of the propulsion, thermal, and power systems that can reduce life cycle cost and overall system operational risk.

Some references are provided below that provide additional details on the characteristics and attributes of the elements described in this paper.

\section{References}

Chamberlain, R. G., Shishko, R., et al, NASA Systems Engineering Handbook, SP-6105, September 1992.

Curtis, L. A., Van Dyke, R. M., Woodcock G. R., Affordable In-space Transportation, NASA TM 108521, October 1996.

Gunn, S.V., Elsevier Science Ltd., Nuclear Propulsion-A Historical Perspective, 2001.

www.elsevier.com/locate/spacepol, accessed June 2006.

Hoffman, E. J., et al, NASA Systems Engineering Handbook, SP-610S, June 1995.

Hammond, W. E., Space Transportation: A Systems Approach to Analysis and Design, AIAA Education Series, AIAA, Reston, Virginia, 1999.

Humble, R. W., Henry, G. N., Larson, W. J., Space Propulsion Analysis and Design, 1st Ed. Rev., McGraw-Hill, New York, N.Y., 1995.

Huzel, Dieter K., Huang, David H., Modern Engineering for Design of Liquid-Propellant Rocket Engines, Volume 147 Progress in Astronautics and Aeronautics, American Institute of Aeronautics and Astronautics, Washington DC, 2004.

Joyner, C.R., Phillips III, J. E. Fowler, R., Borowski, S. K., "TRITON: A TRImodal capable, Thrust Optimized, Nuclear Propulsion and Power System for Advanced Space Missions", AIAA-2004-3863, 40 ${ }^{\text {th }}$ AIAA/ASME/SAE Joint Propulsion Conference, Fort Lauderdale, Florida, July 11-14,2004.

Koenig, D., "Experience Gained From the Space Nuclear Rocket Program (ROVER)", LA-10062-H, Los Alamos National Laboratory, Los Alamos, New Mexico, 1986, pp. 3-32.

Manski, D., Goertz, C., Hulka, J., Goracke, B. D., and Levack, D. J. H., "Cycles for Earth-to-Orbit Propulsion”, AIAA Journal of Propulsion and Power, Vol. 14, No. 5, September-October, 1998.

Martin, J., "Hydrocarbon Rocket Engines for Earth-to-Orbit Vehicles", AIAA Journal of Spacecraft and Rocketry, Vol. 20, No. 3, May-June, 1983.

Parsley, R.C., Zhang, B., "Thermodynamic Power Cycles for Liquid Rocket Engines", $2^{\text {nd }}$ International Symposium on Liquid Rocket Propulsion, ONERA, Chatillion, France, 1995.

Peery, S.D., Joyner, C.R., Parsley, R.C., "Future Technology Directions and Payoffs for Cryogenic Propulsion", ONERA Conference, Paris, France, 1996. 
$46^{\text {th }}$ AIAA/ASME/SAE/ASEE Joint Propulsion Conference

Sackheim, R. L., "Overview of United States Space Propulsion Technology and Associated Space Transportation Systems", AIAA Journal of Propulsion and Power, Vol. 22, No. 6, November-December, 2006.

Sutton, George P., Rocket Propulsion Elements, Fifth Edition, John Wiley \& Sons, New York, 1986. 